\title{
O DISCURSO PEDAGÓGICO/AUTORITÁRIO NA CONSTITUIÇÃO DO SUJEITO
}

\section{Ana Maria Gama Florêncio (UFAL)}

Nosso trabalho norteia-se pelas noções da Análise do Discurso de linha francesa', especialmente no que se refere às posições discursivas ocupadas pelo sujeito. Assumimos, assim, o discurso como lugar de atividade do sujeito, constituído histórica e ideologicamente pelas relações sociais.

As reflexões teóricas aqui abordadas servirão de sustentáculo a uma pesquisa que pretende denunciar algumas situações de poder na instituição Escola, reprodutora de uma ideologia da classe dominante, cerceadora da constituição do aluno-sujeito e mantenedora de uma visão clientelista.

O Discurso Pedagógico é visto por Orlandi (cf. 1987:15) como un discurso autoritário: "discurso do poder (...) falando, nesse discurso, uma voz segura e auto-suficiente. A estratégia, a posição final, aparece como o esmagamento do outro" (op. cit., p. 17). Desse modo, podemos pensar na circularidade de discursos que tendem à estabilização de uma posição voltada para a submissão às autoridades constituídas, que se revestem do poder como meio de impedir a alteração de regras sociais determinadoras das relações de dominação. Essas relações são reproduzidas, pois os próprios subalternos corroboram, por temerem perder algumas benesses que lhes asseguram um ilusório "status". Nesse caso, a ação política - por parte de professores e alunos - fraca, incipiente e insipiente - permanece subordinada à vontade dos setores dominantes e se faz incapaz de efetivar mudanças de valores, expectativas e atitudes.

Essas são questões que, obviamente, têm de passar por uma reflexão sobre a língua e seu funcionamento político-social no contexto escolar. Bourdieu (1983), analisando o papel da linguagem nas relações sociais - fator essencial e determinante do uso da linguagem - estabelece uma analogia com o mercado de bens

Reconhecida como AD. 
materiais, ao colocar a linguagem como um bem cultural, capital lingüístico. Assim, Bordieu (op.cit.) desloca o foco de análise da caracterização da linguagem para a caracterização das condições sociais em que ela ocorre, isto é, pelas relações existentes entre os interlocutores. Sua formulação, nomeada por ele Economia das Trocas Lingüísticas, explica essas relações como forças simbólicas que determinam o poder e o domínio que alguns falantes exercem sobre outros e porque determinados produtos lingüisticos recebem mais valor do que outros. Desse modo, as forças simbólicas, presentes na interação, definem quem pode falar, a quem e como; atribuem valor e poder à linguagem de uns em detrimento da de outros e estabelecem um mercado lingüístico em que os bens que se trocam são palavras que têm um preço, cotado não somente em relação ao que veicula, como também à posição na estrutura social, ocupada por quem as produz. Esse valor depende mais de quem fala, de como fala do que do conteúdo da fala. É um capital de autoridade, reconhecido como legitimo, dependente da posição dos interlocutores nas situações de interação verbal, entre elas e primeiramente na escola, legitimada como lugar de aquisição do capital lingiüístico. Nessa perspectiva, as relações de forças se manifestam na escola por duas vias: nas situações de comunicação pedagógica desenvolvidas no contexto escolar, por ser a língua instrumento fundamental de ensino, e nas relações de inculcação lingüística, quando do ensino formal da linguagem "legítima" ?. São essas relações de força material que definem, então, a legitimidade do discurso, ao tempo que apontam o seu caráter ideológico.

Esse caráter ideológico do discurso, no entanto, será melhor compreendido através de uma ótica que o toma como uma forma de exclusão e inclusão de elementos culturais, numa tentativa de homogeneização de visões de mundo, como unicamente possíveis e aceitas. Assim, o discurso, em seu caráter ideológico, se presta à disseminação de formas específicas de ideologia, a exemplo do Direito, da Política, dos Meios de Comunicação, dos Meios de Produção e, sobretudo, do que mais nos interessa: da Educação. O discurso pedagógico, em sua essência, utiliza-se do jogo ideológico da dissimulação dos efeitos de sentidos, decorrentes de um processo

Legitima, para Bordieu (1983:157-169), como costume cultural ou um uso dominante, reconhecido, ainda que desconhecido como tal. 
histórico e social, sob a forma de informações incontestáveis e verdadeiras, cumprindo a função de reforçar a dominação e legitimar a reprodução da sociedade.

Para Althusser (cf. 1985), as forças produtivas, historicamente constituídas, dão lugar a uma diversificação da força de trabalho, o que justifica pensar a escola como um dos meios de reprodução dessas forças. Nesse sentido, ideologia é pensada como um conjunto de práticas materiais à reprodução de relações (de produção) que implicam a divisão de trabalho - determinadoras do lugar de cada indivíduo, pelo mecanismo de sujeição. Estamos diante, então, do cerne da teoria althusseriana: o sujeito interpelado pela ideologia; sujeito que, ao mesmo tempo que se reconhece como tal, se assujeita a uma instância superior, abstrata, absoluta, mediante um mecanismo produtor do efeito de sujeição.

A essas instâncias Althusser chama de Aparelhos Ideológicos de Estado e aponta-os como responsáveis pela reprodução social, através de mecanismos ideológicos(formas específicas de ideologia) distintos do Aparelho (repressivo) de Estado (governo, ministérios, exército, polícia, tribunais), que funciona prioritariamente pela violência. Os ditos Aparelhos Ideológicos representados pela religião, pelo direito, pela política, pela cultura, pelos sindicatos, pela imprensa, pela família e pela escola estão presentes não só nas idéias, mas também nas práticas, nos rituais dessas instituições, distintas, porém detentoras de uma unidade conferida pela ideologia dominante. Entretanto essa distinção entre dominação pela violência e dominação pela ideologia pode ser melhor vista se pensarmos que ambos dominam pela violência e pela ideologia. Melhor dizendo, a distinção não pode ser feita com diferenças tão demarcadas, mas a partir de uma predominância: o Aparelho (repressivo) de Estado age primariamente pela violência e secundariamente pela ideologia, enquanto os Aparelhos Ideológicos o fazem inversamente.

Convém lembrar, ainda, que essa distinção aponta, de início, para uma outra que se refere às esferas do público/privado. Althusser aponta o Aparelho (repressivo) de Estado pertencendo inteiramente ao domínio público e os Aparelhos Ideológicos de Estado, na sua maioria, como pertencentes à esfera do domínio particular. Ora, essa separação é também tão impossivel quanto a anterior, visto que ambos se confundem e põem em evidência um misto de público e privado, 
sobrepostos em razão de um funcionamento ideológico, sob controle da classe dominante. As instituições privadas não prescindem de leis que emanam do poder público e fundamentam seus estatutos; as instituições públicas, por sua vez, não têm seu funcionamento livre da interferência do privado, em virtude de os sujeitos que as compõem serem, de alguma forma, impregnados pela lógica do capital.

Althusser afirma ser a escola o aparelho ideológico que assumiu "a posição dominante nas formações capitalistas maduras" (1985: 71), pelo fato de que

Ela se encarrega das crianças de todas as classes sociais desde o Maternal, e desde o Maternal ela Ihes inculca, durante anos, precisamente durante aqueles em que a criança è mais 'vulnerável', espremida entre o aparelho de Estado familiar e o aparelho de Estado escolar, os saberes contidos na ideologia dominante (op. cit.,79).

Ao que ele acrescenta que, no final do processo escolar, essas crianças farão parte da "produção"3, ou seja, estarão inseridas, de imediato, em profissões ou prosseguirão nos estudos, assumindo cada um a ideologia "que convém ao papel que ele deve preencher na sociedade" (ibidem), sem que se dêem conta de que estar no mundo significa poder refletir sobre suas ações. As relações do sujeito com o mundo, a sua constituição, passam por uma inculcação ideológica, mecanismo de ocultação, de apagamento da interpretação. Melhor dizendo, a ideologia da classe dominante, através da evidência de um sentido único, transparente, impede o sujeito de interpretar a realidade que o cerca, de estabelecer uma relação crítica com a língua, a história e os sentidos.

Desse modo, a escola, como instituição primeira, contribui para a reprodução e manutenção de uma ideologia dominante no processo de constituição dos alunos/sujeitos. As normas de comportamento, próprias à divisão do trabalho, conforme a ordem estabelecida pela classe dominante, ou seja, a reprodução de uma submissão (assujeitamento) a uma ideologia dominante, também são ensinadas pela escola, ao lado de conhecimentos e técnicas. Há, na escola, um direcionamento para a visão de um sujeito responsável pelos seus atos, o que aponta para o apagamento de uma trama anterior complexa que, de antemão, impede qualquer análise dos

Grifo do autor. 
determinantes histórico-discursivos. É dessa forma que o discurso do poder atravessa a educação, assegurando a sua reprodução ideológica, definindo seus objetivos e seus conteúdos e cerceando possibilidades de críticas ao processo histórico social.

Assim, Althusser não aponta nenhuma outra posição para a escola, a não ser a de um assujeitamento total, como um lugar de mera reprodução da ideologia dominante. Há, então, um determinismo, uma redução, uma impossibilidade de uma renovação de forças, um não reconhecimento de que as estruturas sociais, em constantes conflitos, têm, constitutivamente, uma natureza dinâmica, conseqüentemente, mutante. Portanto, o conceito althusseriano de sujeito, considerando os poderes assujeitadores, ignora a possibilidade - no caso da escola de professores e alunos, em sua constituição histórico-social, agirem e interferirem nos destinos da instituição, num permanente diálogo.

As relações com o ̧̣outro estão marcadas em Bakhtin (1990) por um princípio dialógico, por ser a alteridade imprescindível na definição do homem. O dialogismo bakhtiniano articula as relações entre o mundo e o homem, pela via do psiquismo, habitado pelo signo ideologicamente marcado pelas estruturas sociais. Indivíduos socialmente organizados interagem e produzem a enunciação, sempre a partir do prisma do meio social que engloba os interlocutores. A palavra é definida por esse autor como composta de duas faces: procede de alguém, dirige-se a alguém, constitui o produto da interação entre locutor e ouvinte:

a palavra é uma espécie de ponte lançada entre mim e os outros. Se ela se apóia sobre mim numa extremidade, na outra apóia-se sobre o meu interlocutor (op. cit.).

O locutor é submetido às pressões sociais e ideológicas e é pela expressão que se organiza sua atividade mental. Qualquer que seja o aspecto da expressão-enunciação ele será determinado pelas condições reais de enunciação, melhor dizendo, pela situação social mais imediata, determinante do grau de consciência dos interlocutores, que, por mais simples que seja, pode até dispensar uma expressão exterior, mas não dispensa uma expressão ideológica. Assim é que, para Bakhtin, o pensamento não existe fora de sua expressão potencial, conseqüentemente, da orientação social dessa expressão. O percurso que se dá entre a atividade mental (conteúdo a exprimir) e sua objetivação externa (a enunciação) situa-se completamente em território social. 
Essas formulações levam Bakhtin a uma nova visão a respeito da consciência e da ideologia: fora de sua objetivação, de sua realização num material determinado (o gesto, a palavra, o grito), a consciência é pura ficção, por não levar em consideração os dados concretos da expressão social. Porém, a consciência como expressão social materializada passa a ser um fato objetivo, dotado de considerável força social, muito embora não se possa pensá-la acima do ser, nem como determinante de sua constituição; ela é parte das forças desse ser.

A atividade mental centrada na vida cotidiana e sua expressão é denominada por Bakhtin ideologia do cotidiano, constituidora do domínio da palavra interior e exterior, em desordem no sistema, atrelada aos nossos atos, gestos e cada estado de consciência. Esse caráter ideológico, historicamente marcado, conferido ao signo lingüístico - dialógico por natureza - leva Bakhtin a concluir que em todo signo se confrontam valores contraditórios. Para ele, " a palavra é uma arena onde se desenvolve a luta de classes" (op. cit.). As diferentes classes sociais, ao mesmo tempo que fazem uso da palavra para transmitir seus valores, ocultam o dialogismo que constitui a língua, mas que se mostra no discurso ideologicamente marcado. Como se pode ver, o dialogismo acontece na interação verbal entre os interlocutores (enunciador/enunciatário) e aponta, assim, para um sujeito histórica e ideologicamente constituido, habitado por diferentes vozes sociais.

É a presença do outro, já apontado por Bakhtin como parte constitutiva do sentido e como outra voz, que habita o sujeito e seu discurso. O discurso autoritário, no entanto, como verdade incontestável, tenta abafar as diferentes vozes em conflito e as diferentes posições que podem ser assumidas pelos sujeitos, num processo de interação verbal e de constituição do sentido.

O conceito da natureza dialógica da linguagem é, como se pode ver, um repensar e uma desconstrução que Bakhtin empreende contrapondo-se ao formalismo-estruturalista e ao ideologismo, concluindo que é o fenômeno social da interação verbal que constitui a verdadeira substância da língua, e não um sistema abstrato de formas lingüísticas, uma enunciação monológica isolada ou um ato psicofisiológico de sua produção - análise que ele faz das duas linhas mestras de pensamento fillosófico-lingüístico: Objetivismo Abstrato e 
Subjetivismo Individualista. O primeiro, formulações lingüísticas saussureanas, rejeita a enunciação, o ato de fala, toma como objeto de estudo a língua, como sistema lingüístico puro, pois somente assim pode dar conta dos fatos da língua; o segundo leva em consideração a fala, mas como ato individual, tentando explicá-la a partir das condições do psiquismo individual do sujeito falante. Bakhtin afirma ser a enunciação de natureza social, donde se conclui que o objeto da lingüistica não é, para esse autor, a língua, mas a fala como interação verbal - não como ato individual. Como conseqüência dessa conceituação, tem-se a introdução de sujeito e contexto historicamente constituídos.

No entanto, o sujeitó bakhtiniano, embora seja concebido como passível da intervenção do(s) outro(s), através de seu interlocutor, não sendo, portanto, fonte de seu sentido, não se organiza, ainda, "como lugar de passagem de discursos submersos" (Dahlet, 1997:60). A exterioridade materializada na consciência aponta para um sujeito polifônico, lugar de concentração e substituição de vozes já existentes. Entretanto, essa construção do sujeito determinado pelo outro já introduz um deslocamento que oferece significativas contribuições para a compreensão do sujeito do discurso, pela via reflexiva da Análise do Discurso, por ser esta a disciplina que coloca como objeto de estudo o discurso pensado em relação à sua exterioridade, ou seja, numa dimensão histórico-social da identificação do sentido e do sujeito. É notório, pois, que as reflexões a respeito do discurso tiveram início em Bakhtin, diante de suas formulações teóricas sobre o princípio dialógico, afirmando que as ciências humanas devem voltar-se para o homem como produtor de discursos ideologicamente (contexto histórico, social, cultural) constituídos, por isso essencialmente dialógicos.

A ideologia, como condição de constituição dos sujeitos e dos sentidos, organiza uma sociedade. No entanto, ao ocultar sua existência, dentro de seu próprio funcionamento, não deixa entrever conflitos. Quando esses conflitos se põem à mostra, é porque a ideologia passa ao seu sentido restrito da uma classe dominante envolvida com a organização do trabalho. Como ideologia dominante, busca, então, organizar conflitos e apagar as diferenças, submetendo o sujeito às determinações sociais. 
Convém notar, porém, que essas determinações sociais não anulam as atividades dos sujeitos, pelo fato de que os mesmos se constituem pela história de suas instituições. Em sua singularidade, os sujeitos de classe participam da produção de sentidos, o que permite sua ação sobre a língua e sobre o social, pois ao tempo que o sujeito significa o mundo, ele também se significa e afeta a realidade. mediado pela ideologia.

Segundo Haroche (et al. 1971:102),

Cada formação ideológica constitui assim um conjunto complexo de atitudes e de representações que não são nem individuais nem universais mas se relacionam mais ou menos às posições de classe em conflito umas em relação às outras.

As formações ideológicas têm como um de seus elementos de composição uma ou várias formações discursivas interligadas. Para Pêcheux (1988: 160),

Formação Discursiva é aquilo que, numa formação ideológica dada, isto é, a partir de uma posição dada numa conjuntura dada, determinada pelo estado de luta de classes, determina o que pode e deve ser dito.

Uma Formação Discursiva, termo introduzido por Foulcault (1971) e transportado por Pêcheux para a AD, pode ser pensada como um lugar de atuação das formações ideológicas, reguladora de sentidos e de afirmações aceitáveis ou não. Mas as formações discursivas estão em constante movimento de ressignificação, aproximando ou distanciando sentidos, pelos processos de paráfrase e polissemia, respectivamente. O primeiro constitui uma retomada e reformulação dos enunciados, preservando sua formação discursiva: o segundo dá lugar à multiplicidade de sentidos transitando entre diferentes formações discursivas, que podem apontar para uma formação ideológica ou para um confronto entre elas. Assim,

Isso eqüivale a afirmar que as palavras, expressões, proposições, etc., recebem seu sentido da formação discursiva na qual são produzidas (...) formaçōes discursivas que representam 'na linguagem' as formaçōes ideológicas que Ihes são correspondentes (Pêcheux, 1988:160,161).

Esse movimento constante de ressignificação é tratado por Orlandi (1996) como processo de reconfiguração e gestos de interpretação, de significação, que tanto podem aproximar os sentidos 
como distanciá-los. Quando aproxima, estabelece os sentidos como se as formações discursivas fossem fechadas em si mesmas, totalmente estabilizadas; quando distancia, manifesta-se o diferente, o confronto de sentidos. As formações discursivas são, portanto, um lugar de ancoragem onde esses processos acontecem, evitando que se dê uma total separação entre os sentidos dos processos discursivos, ao mesmo tempo que não permitem que esses sentidos se confundam com outros já determinados na memória discursiva (o interdiscurso).

O deslocamento entre formações discursivas é de tal forma que una serve de matéria-prima à outra, porque é próprio delas dissimular, na ilusória transparência do sentido que se forma, o fato de que se fala sempre sob a dependência do interdiscurso(Cf. Courtine). Este último, como algo já dito que possibilita um novo dizer ressignificado no sentido instituído pelo sujeito em uma situação discursiva. A heterogeneidade e contradição constituintes das formaçóes discursivas impedem a demarcação de seus limites, pondoas em constante movimento. Assim, segundo Pêcheux (1988:162),

Toda formação discursiva dissimula, pela transparência do sentido que nela se constitui, sua dependência com respeito ao "todo complexo com dominante' das formações discursivas, intrincado no complexo das formaçōes ideológicas.

Esse autor propõe, então, chamar o "todo complexo com dominante" de interdiscurso, processo cuja estrutura se organiza também na desigualdade-contradição-subordinação, sob a forma de pré-construido (sempre-já-ai, materialidade, construção anterior, que se opõe ao construído no enunciado) ${ }^{4}$, e da articulação (o sujeito em sua relação com o sentido). Para Orlandi (1998: 12),

[...]o interdiscurso se apresenta como séries de formulações que derivam de enunciações distintas e dispersas que firmam em seu conjunto o domínio da memória (do saber discursivo), esse dominio constitui a exterioridade discursiva para o sujeito do discurso.

No entanto, o já-dito, o interdiscurso (discursos outros de uma mesma ou de múltiplas formações discursivas) incorporado pelo sujeito e revelado como "diferente" permite que se desvendem as relações de

O pré-construído mostra um sujeito inscrito no já-dito, mas também possibilita que o sujeito coloque suas marcas no discurso, como traços do interdiscurso no discurso. 
forças, de dominação, de polemicidade mantidas entre os discursos, implícitas ou não, atravessadas no intradiscurso. Os dizeres são acionados afetando o modo como o sujeito produz sentidos, convocados por uma situação discursiva e presentificados no intradiscurso. Este último, como processo que oferece ao sujeito a condição de modificar o repetível, o já-dito reiterável, ressignificando-o e, conseqüentemente, significando-se. O discurso é, então, produzido na articulação entre o interdiscurso de uma ou de diferentes formação(ões) discursiva(s) e o intradiscurso de uma seqüência discursiva produzida pelo sujeito, como um conjunto de determinações, uma unidade da diversidade de relações do sujeito com a língua e a história, através da ideologia, que "torna possivel a relação entre o pensamento, a linguagem e o mundo. Ou. em outras palavras, reúne sujeito e sentido" (Orlandi, 2001:96).

O discurso, pois, em sua carga ideológica e histórica das relações sociais, constitui-se na articulação entre o lingüístico e o social e produz sentidos numa aparente unidade e numa ilusória transparência que somente poderão ser desvendadas na análise do funcionamento discursivo e das formações discursivas pelas quais os sujeitos estão atravessados.

A ilusória transparência, ou seja, uma realidade discursiva ilusória criada pelo sujeito é vista por Pêcheux (op.cit.:173) como dois tipos de esquecimento que o afetam: o esquecimento 11 ." $I$ - o sujeito imagina-se fonte de seu dizer, ou melhor, do sentido do que diz, sem perceber que, na verdade, está retomando e ressignificando outros discursos que por ele circularam. Esse processo de apagamento é de natureza ideológica e inconsciente; o esquecimento "l." 2- o sujeito utiliza-se de estratégias discursivas para explicar o que diz, para formular o seu discurso de uma maneira mais adequada, porque, em sua ilusão, ele julga que diz apenas aquilo que ele próprio seleciona. No interior da formação discursiva que o domina, o sujeito realiza escolhas de determinadas formas discursivas e "esquece" outras. Essa ilusão é para a AD uma ilusão necessária, por ser o lugar da subjetividade, da constituição do sujeito sócio-historico.

A identificação e posicionamento do sujeito no mundo acontece na formação discursiva que o constitui, domina, encobre sua dependência a outras formações discursivas, cumprindo, assim, seu papel, através da ilusória transparência da unidade do sentido, a cujo processo de formação o sujeito não tem acesso. Para a AD, toda 
formação discursiva pressupõe uma forma-sujeito, denominação que recorre à forma pela qual o sujeito se posiciona como sujeito do discurso. pela sua identificação com essa formação discursiva. ou scja. a forma pela qual o sujeito procura definir sua identidade, sua posição no discurso. No entanto, convém notar que esse processo de identificação não se fecha em apenas uma formação discursiva, mas entre várias: um sujeito singular identifica-se a um sujeito universal, com possibilidades de novas relações de enunciados já constituidos em formações discursivas com a produção de outros enunciados, pela interpretação, transformação e produção de novos sentidos. Ou seja, o sujeito universal é aquele que se constitui no seio de uma formação discursiva e assegura o que cada un conhece, pode ver ou compreender e pode ser dito; o sujeito singular identifica-se ao sujeito universal. mas, no movimento da identificação, apaga (ou esquece) sua liliação(cf. Courtine, 1981).

Assim, o sujeito, embora não possa ser pensado como fonte de seu dizer, não deixa de exercer um papel na produção do discurso, em todo ato social. É um sujeito dividido, desdobrado nas várias posições que ocupa numa formação discursiva em constante movimento, mas sempre aberta ao atravessamento de outras formações discursivas, embora a identidade do sujeito se mantenha na "ilusão necessária" da unidade discursiva, da origem e fonte do sentido. No reconhecimento dessas várias posições assumidas pelo sujeito, aponta-se para uma heterogeneidade constitutiva do discurso, encoberta por una coerência que harmoniza e apaga as diferentes vozes, pelos processos parafirásticos, sinonimicos ou pelas substituiçòes. Tais processos têm como resultado a produção de efeitos de sentido.

$\Lambda$ heterogeneidade constitutiva do sujeito e do discurso é vista por Pêcheux em seus últimos trabalhos, aproximando-se de formulações de Authier-Revuz (1982), que, amparada na concepção dialógica de Bakhtin, coloca-se, como este último, numa visão exterior à Lingüística. Para tanto, alia-se à Psicanálise e às Ciências Sociais no questionamento à unicidade do sentido e à homogeneização discursiva.

A Psicanálise entende o sujeito como efeito da linguagem, "em busca pelo sentido, por um fechamento provisório, o que se dá a partir dos sentidos 'já lá (interdiscurso), os quais neste movimento são (re)significados" (Carreira, 2000:1), mas sempre investigados na 
complexidade de uma fala heterogênea. O discurso é analisado pelo seu avesso, que aponta para o inconsciente e não para o dizer explícito. Em Lacan, o sujeito se constitui no que um significante significa para outro significante, no que emerge entre os significantes (cf. Lacan 1969-1970). O sujeito oscila, mas não se estabiliza numa posição, porque, ao se submeter ao significante, não está nele nem fora dele, mas em suspenso, emergindo e imergindo, sempre latente, deixando entrever apenas o rastro de sua presença/ausência:

O significante produzindo-se no campo do Outro $^{5}$ faz sempre surgir o sujeito de sua significaçāo [...] petrificando-o pelo mesmo movimento com que o chama a funcionar, a falar, como sujeito (Lacan, 1964:197).

Ao situar o sujeito do inconsciente, Lacan procurou bases científicas sólidas em sua releitura de Freud e é nesse quadro de busca da cientificidade que se dá seu encontro com Saussure, visto que suas reflexões sobre a língua acabam convergindo. É a partir da concepção de língua de Saussure, como sistema de signos diferenciais, que Lacan reformula sua noção de sujeito. Esse autor recorre, ainda, ao "segundo Saussure", o dos anagramas - que desperta para a ocorrência de um outro texto subjacente aos textos de poetas gregos e latinos, como uma pesquisa de palavras sob as palavras - para uma melhor compreensão da questão freudiana do inconsciente, embora Saussure não tenha abordado o problema por esse ângulo. A Teoria do Valor; onde Saussure deixa entrever uma inegável presença do sujeito e do sentido, despertou em Lacan um especial interesse, porque, tanto nessa Teoria quanto na Psicanálise, a produção do sentido se dá independentemente do referente.

Assim, partindo do princípio de que o sentido pode sempre ser outro - princípio muito presente nas teorizações até aqui apontadas nesse trabalho -, recorremos, também, como já dito, a Authier-Revuz, cujas reflexões sobre dialogismo bakhtiniano e, principalmente, com base em fundamentos da Psicanálise, analisam as marcas explícitas e implícitas da materialidade discursiva nomeando-as heterogeneidade mostrada e heterogeneidade constitutiva. A primeira (o uso de aspas, glosas, os enunciados metadiscursivos) como intervenção do outro, ou

Em Lacan, o Outro é o lugar do significante, porque ele jamais é o mesmo; é pura alteridade, é o lugar do simbólico. 
de outras "vozes" no discurso, como confronto da identidade/alteridade do sujeito:

o fragmento é colocado entre aspas, em itálico ou (às vezes) glosado por uma incisa. (...) o fragmento é integrado à cadeia discursiva sem ruptura sintática: de estatuto complexo, o elemento mencionado é inscrito na continuidade sintática do discurso ao mesmo tempo que, pelas marcas, que neste caso, não são redundantes, é remetido ao exterior do discurso (Authier-Revuz, 1982: 29).

A heterogeneidade mostrada articula-se com a heterogeneidade constitutiva da linguagem, não vista na materialidade, mas possível de ser verificada na relação que todo discurso mantém com outros discursos. Assim, o sujeito, na ilusão de ser o centro de seu dizer, localiza e delimita o espaço do outro, procurando definir o seu próprio território.

Esses dois planos de heterogeneidade são também considerados por Maingueneau (1989), classificando a primeira heterogeneidade mostrada -, através de múltiplos fenômenos dependentes que constituem suas marcas e a segunda heterogeneidade constitutiva -, como "formulando hipóteses, através do interdiscurso, a propósito da constituição de uma formação discursiva" (op. cit.: 75).

É um funcionamento desconhecido pelo sujeito, na ilusão de ser tonte de seu discurso que mostra uma relação entre os dois planos de heterogeneidade e aponta também para a ilusão de um sentido único, porque, como diz Pêcheux, "todo enunciado é intrinsecamente suscetivel de tornar-se outro, diferente de si mesmo, se deslocar discursivamente de seu sentido para derivar para um outro (...)" (1990:53).

Isso nos faz ver que Pêcheux coloca a metáfora como constitutiva do sentido, como transferência e não como desvio. É na possibilidade do deslocamento discursivo do sentido que acontece o efeito metafórico, como deslize da ordem do simbólico. O efeito metafórico é, portanto, lugar da interpretação, da ideologia, da historicidade, em que se pode ver a relação língua/discurso, pelo fato de não poder existir sentido sem a possibilidade de mudança do mesmo, ou seja, de interpretação, o que nos faz compreender que o trabalho de interpretação da materialidade lingüística, segundo a $\mathrm{AD}$, 
é o ponto de encontro para o funcionamento da língua com o discurso. A língua, discursivamente falando, como sistema sintático (organização), passivel de jogo; o discurso como lugar de efeito dos sentidos lingüístico, histórico e ideologicamente constituídos, revelador, em decorrência da remissão a outro(s) discurso(s), o que o torna múltiplo e único ao mesmo tempo, por ser irrepetível.

Se o sentido, ao se constituir, constitui o sujeito. é também no equivoco, no efeito de uma relação significante que está a instância do sujeito. Isso nos leva, então, a entender a razão pela qual a $\mathrm{AD}$ se relaciona com a Psicanálise: é no equivoco, no deslize constitutivo do sentido, na falha que se pode ver, claramente, a relação com o inconsciente e é ainda no equívoco que se pode perceber a relação da história com a ideologia.

Essa maneira de pensar discurso, sujeito e sentido leva-nos a interpretar o discurso pedagógico vigente como uma forma de impedir que a escola analise e conduza seus conflitos, suas contradições. Remetemo-nos, então, ao discurso como efeito de sentidos e ao sujeito do discurso como afetado pelo inconsciente. O discurso da escola, constituído ideologicamente, é, assim, transferidor e mantenedor de uma posição hegemônica, da qual os sujeitos não se dão conta. No entanto, o mecanismo das relações entre lingua/história/inconsciente/ideologia/, constituintes do discurso como efeito de sentidos, que não são evidentes nem transparentes, mas que, exatamente por constituírem uma ilusão, abrem para uma possibilidade de tornarem-se outros, pois oferecem ao analista do discurso um trabalho de compreensão do gesto de interpretação, de como o dispositivo analítico permitirá o trânsito entre as prováveis posições do sujeito. 


\section{REFERÊNCIAS BIBLIOGRÁFICAS}

ALTHUSSER, Louis. Aparelhos ideológicos de Estado.2.ed. Rio de Janeiro: Graal, 1985.

AUTHIER-REVUZ, Jacqueline. Heterogeneidade(s) enunciativa(s). Cadernos de Estudos Lingiä́sticos. Campinas, EL, n. 19, p.25-42, 1990 .

BAKHTIN, Mikhail (Volochinov). Mar:xismo e filosofia da linguagem. 5.ed. São Paulo: Hucitec, 1990.

BORDIEU, Pierre. Sociologia. ORTIZ, Renato (org.), FERNANDES, Florestan (coord.). São Paulo: Ática, 1983.

CARREIRA, Alessandra Ferreira. Sobre a singularidade do sujeito da posiçúo de autor: Ribeirão Preto / São Paulo. Universidade de Ribeirão Preto / Universidade de São Paulo, 2000. (mimeo.)

COURTINE, Jean Jacques. Analyse du discours politique (le discours communiste adressés aux chrétiens). Language, Paris, Larousse, n. 62, 1981 .

HAROCHE, Claudine; HENRY, Paul; PÊCHEUX, Michel. La semantique e la coupure saussurienne: langue, language, discours. Language, Paris, Didier/Larousse, n. 24, 1971.

MAINGUENEAU, Dominique. Novas tendências em análise do discurso. Campinas: Pontes, 1989.

ORLANDI. Eni Pulcinelli. A linguagem e seu funcionamento, as formas do discurso. Campinas: Pontes, 1987.

ORLANDI, Eni Pulcinelli. Interpretação, autoria, leitura e efeitos do trabalho simbólico. Petrópolis: Vozes, 1996.

ORLANDI, Eni Pulcinelli (org.). A leitura e os leitores. Campinas: Pontes, 1998.

ORLANDI, Eni Pulcinelli. Análise de Discurso, principios e procedimentos. Campinas: Pontes, 2001.

PÊCHEUX. Michel, Semântica e discurso: uma crítica à afirmação do óbvio. Campinas: Ed. Unicamp, 1988.

PECHEUX, Michel. O discurso: estrutura ou acontecimento. Campinas: Pontes, 1990. 